Check for updates

Cite this: RSC Adv., 2019, 9, 28165

Received 1st July 2019

Accepted 2nd September 2019

DOI: 10.1039/c9ra04975d

rsc.li/rsc-advances

\title{
Enhanced hydrogen evolution from water splitting based on ZnO nanosheet/CdS nanoparticle heterostructures $\dagger$
}

\author{
Yinwei Wang, ${ }^{a}$ Hang Ping, (D) *a Tiening Tan, ${ }^{a}$ Wenxuan Wang, ${ }^{a}$ Peiyan Ma ${ }^{b}$ \\ and $\mathrm{HaO} \mathrm{Xie}^{\mathrm{D}}{ }^{\mathrm{b}}$
}

\begin{abstract}
As environmental and energy problems have worsened worldwide, research for developing renewable energy has become urgent. Presently, the primary focus of such research is directed towards the photocatalytic decomposition of water to produce hydrogen as an energy source. Herein, $\mathrm{ZnO}$ nanosheet/CdS nanoparticle heterostructures were synthesized by a mild wet chemical reaction and displayed a high photocatalytic efficiency $\left(1040 \mu \mathrm{mol} \mathrm{g}^{-1} \mathrm{~h}^{-1}\right)$ without Pt loading under visible light radiation. The structure was prepared by first constructing two-dimensional nanocrystalline $\mathrm{ZnO}$ flowers and then loading CdS nanoparticles onto the nanocrystals. Results show that this structure can facilitate the separation of photogenerated electrons and holes and improve the photocatalytic efficiency and stability of the materials in the photocatalytic decomposition of water. By changing different experimental conditions to prepare a variety of samples and test their properties, we can analyze the optimal parameters for the preparation of this material.
\end{abstract}

\section{Introduction}

The detrimental effects of environmental pollution and global warming on living organisms, particularly humans, have become a major concern and require immediate attention. The root of these problems is the indiscriminate emission of greenhouse and harmful gases from the combustion of fossil fuels. Fossil fuels are non-renewable resources, and their excessive consumption will lead to a serious energy crisis. As a new clean and efficient energy source, hydrogen has attracted wide attention because of its high combustion heat and clean combustion products. ${ }^{1-6}$ In 1972, Fujishima first achieved hydrogen production through the photocatalytic decomposition of water using a titanium dioxide semi-conductor as an electrode under ultraviolet irradiation. ${ }^{7}$ Since then, hydrogen evolution from water splitting based on photocatalytic technology has been widely and deeply studied. Although this technology appears promising to solve global energy and environmental problems, determining and designing optimal semiconductor photocatalysts to efficiently convert solar energy to hydrogen energy remain a significant task.

${ }^{a}$ State Key Laboratory of Advanced Technology for Materials Synthesis and Processing, Wuhan University of Technology, Wuhan 430070, China. E-mail: pinghang0716@163. com

${ }^{b}$ School of Chemistry, Chemical Engineering and Life Science, Wuhan University of Technology, Wuhan, 430070, China

$\dagger$ Electronic supplementary information (ESI) available. See DOI: 10.1039/c9ra04975d
In a representatively photocatalytic process, semiconductor materials experience roughly three steps: (1) sunlight excites an electron from the conduction band to the valence band and forms a photogenerated electron-hole pair; (2) photo-generated electrons and holes transport or recombine on the surface and in the bulk of a semiconductor, then migrate to the surface of the semiconductor; (3) photogenerated carriers, migrating to the surface of the semiconductor, induce the redox reaction. ${ }^{8,9}$ Therefore, the selection of a semiconductor photocatalyst is determined by band gap, structure, stability, among other factors. The band gap width directly determines the efficiency of the photogenerated electron-hole, where a wider band gap requires a higher excitation energy, and most visible light cannot be absorbed effectively. The structure or morphology of the semiconductor greatly affects the absorption efficiency, the carrier transport path or rate of carriers, electron-hole recombination, etc. For example, one-dimensional nanostructures can facilitate electron transport and the separation of photogenerated carriers. ${ }^{10}$ In the process of photocatalysis, redox reactions on the surface of semiconductors will lead to photocorrosion of the semiconductor; thus, it is very important to enhance photostability of the semiconductor photocatalyst.

Numerous studies have fabricated various semiconductor photocatalysis, including $\mathrm{TiO}_{2}, \mathrm{ZnO}, \mathrm{C}_{3} \mathrm{~N}_{4}, \mathrm{CdS}, \mathrm{MoS}_{2}$ and graphene/black phosphorus in order to improve the efficiency of hydrogen production. ${ }^{11-18} \mathrm{ZnO}$ is a common photocatalyst semiconductor with a direct band gap, which can effectively avoid the low electron transition probability in indirect semiconductors, and offers advantages of high 
photosensitivity, low cost, non-toxic environmental protection, etc. However, the wide band gap $(3.2 \mathrm{eV})$ and fast recombination of photogenerated carriers severely inhibit ZnO semiconductors' photocatalytic efficiency. ${ }^{19-22}$ While CdS can split water under visible light due to its narrow band gap $(2.4 \mathrm{eV})$, its photocorrosion seriously limits its recycling utilization efficiency as a photocatalyst. ${ }^{23}$ Considering the advantages of both materials, CdS has been adopted to sensitize ZnO in many studies. Previous literatures have reported the syntheses of $\mathrm{ZnO}$ and $\mathrm{CdS}$ heterostructures to form respective hybrid systems, which are used to improve the efficiency of hydrogen production and stability. ${ }^{24-26}$ For instance, $\mathrm{X}$. W. Wang et al. prepared $\mathrm{ZnO} / \mathrm{CdS}$ nanocrystalline heterostructures by a wet chemical reaction at $60^{\circ} \mathrm{C}$ for $24 \mathrm{~h}$. After loading noble metal Pt, the hydrogen production efficiencies of CdS and $\mathrm{ZnO}$ were 14 and 40 times higher than that of single $\mathrm{ZnO}$, respectively. ${ }^{25} \mathrm{D}$. D. Ma et al. prepared $\mathrm{CdS} / \mathrm{ZnO}$ heterostructures by coating CdS quantum dots on ZnO nanosheets via a hydrothermal method assisted by ultrasound. The hydrogen production efficiency of this material was $22.12 \mathrm{mmol} \mathrm{g}^{-1} \mathrm{~h}^{-1}$, which is 13 and 138 times higher than that of single ZnO. ${ }^{3}$ S. Mukhopadhyay et al. prepared disk $\mathrm{ZnO}$ by an ultrasonic chemical method, then deposited CdS nanoparticles on the disk surface using a hydrothermal method. The hydrogen production efficiency of the composite was 22 times higher than that of single $\mathrm{ZnO}$ in visible light. ${ }^{26}$ Although these results of the above works are promising, the synthesis of $\mathrm{ZnO} / \mathrm{CdS}$ heterostructures requires high temperatures and complex preparation methods, which are energy-consuming procedures.

Herein, we prepared $\mathrm{ZnO} / \mathrm{CdS}$ heterostructures through a simple synthesis method under low temperatures. The flowerlike ZnO was assembled by single-crystal nanosheets with a thickness of $10 \mathrm{~nm}$, followed by the uniform deposition of CdS nanoparticles with a diameter of $5 \mathrm{~nm}$ on the surface of the nanosheets. The loading content of CdS can be controlled by incubating different concentrations of $\mathrm{ZnO}$ nanosheets in the reaction solution. The $2 \mathrm{D}$ nanosheets provide an ideal platform for confining the growth of $\mathrm{CdS}^{27}$ and facilitate the fast transport of carriers to prohibit the recombination of photogenerated electrons and holes. As expected, the prepared CdS/ ZnO heterostructure without Pt loading exhibits the highest hydrogen evolution rate of $1040 \mu \mathrm{mol} \mathrm{g}^{-1} \mathrm{~h}^{-1}$, about four times that of solely CdS under visible light irradiation. In addition, the $\mathrm{CdS} / \mathrm{ZnO}$ heterostructure we prepared also has excellent cycle stability. The results demonstrate that the $\mathrm{ZnO}$ nanosheets/CdS nanoparticles heterostructure has good potential as a photocatalyst for hydrogen evolution. The main text of the article should appear here with headings as appropriate.

\section{Experimental section}

\section{Chemical reagent}

Zinc nitrate $\left[\mathrm{Zn}\left(\mathrm{NO}_{3}\right)_{2} \cdot 6 \mathrm{H}_{2} \mathrm{O}\right]$, sodium hydroxide $(\mathrm{NaOH})$, cadmium chloride $\left(\mathrm{CdCl}_{2} \cdot 2.5 \mathrm{H}_{2} \mathrm{O}\right)$, and sodium sulfide $\left(\mathrm{Na}_{2}\right.$ $\mathrm{S} \cdot 9 \mathrm{H}_{2} \mathrm{O}$ ) were purchased from Sinopharm Chemical Reagent Co., Ltd. without further purification.

\section{Synthesis of flower-like ZnO}

$\mathrm{Zn}\left(\mathrm{NO}_{3}\right)_{2} \cdot 6 \mathrm{H}_{2} \mathrm{O}$ was selected as the zinc source to prepare a $0.1 \mathrm{M} \mathrm{Zn}^{2+}$ solution, into which $1.0 \mathrm{~g} \mathrm{NaOH}$ solid powder was added. After stirring for $5 \mathrm{~min}$, the mixed solution was placed into a water bath at $40^{\circ} \mathrm{C}$ for $6 \mathrm{~h}$. $\mathrm{NaOH}$ was used to control the hydration of zinc ions by changing the $\mathrm{pH}$ of the solution. The precipitate was centrifuged, washed with deionized water three times, then dried in a lyophilizer (denoted as ZnO@2 : 5) to obtain the powder. In order to explore the effect of $\mathrm{NaOH}$ on the morphology of $\mathrm{ZnO}$ products, various amounts of $\mathrm{NaOH}(0.5$, $0.6,0.8,1.2$, and $1.6 \mathrm{~g}$ ) were added into the $\mathrm{Zn}^{2+}$ solution under the same conditions then denoted as ZnO@1:5, $1: 6,1: 8$, $2: 6$, and $2: 8$, respectively.

\section{Synthesis of $\mathrm{ZnO} / \mathrm{CdS}$ heterostructures}

Flower-like $\mathrm{ZnO}$ powders assembled by nanosheets were chosen as the raw material for the preparation of $\mathrm{ZnO} / \mathrm{CdS}$ composites. $50 \mathrm{mg} \mathrm{ZnO}$ powder was poured into a beaker containing $50 \mathrm{ml}$ $\mathrm{Cd}^{2+}$ solution. To control the loading content of $\mathrm{CdS}$, we varied the concentration of $\mathrm{Cd}^{2+}$ in the solution $(200,120,100,50,20$, 12.5 , and $10 \mathrm{mM}$ ) in a reaction with $\mathrm{ZnO}$ for $1 \mathrm{~h}$. The products were centrifuged and washed, then dispersed in $20 \mathrm{ml} \mathrm{S}^{2-}$ solution $(20 \mathrm{mM})$, and agitated for $1 \mathrm{~h}$ to obtain the final powder. Finally, the reactants were centrifuged, washed, and dried. As the control group, CdS powder was synthesized through mixing $20 \mathrm{mM} \mathrm{Cd}^{2+}$ and $20 \mathrm{mM} \mathrm{S}^{2-}$ solution.

\section{Characterization}

X-ray diffraction (XRD) patterns were obtained using Bruker D8 Advance with $\mathrm{Cu} \mathrm{K} \alpha$ radiation $(V=40 \mathrm{kV}, I=40 \mathrm{~mA})$ in the range of $15-75^{\circ}$. Surface morphology information was revealed by field emission scanning electron microscopy (FESEM; Hitachi $\mathrm{S}-4800$ ) at $5 \mathrm{kV}$. High resolution transmission electron microscopy (HRTEM) examination was carried out with a JEOL JEM $2100 \mathrm{~F}$ at $200 \mathrm{kV}$ equipped with an energy-dispersive spectroscopy (EDS) detector. Specific surface area was determined by an ASAP 2020M adsorption apparatus using the BrunauerEmmet-Teller (BET) method. X-ray photoelectron spectroscopy (XPS) measurements were conducted using a ThermoFisher Escalab 250Xi.

\section{Photocatalytic hydrogen generation}

The photocatalytic splitting of water to produce hydrogen occurred in a closed glass flask using a $300 \mathrm{~W}$ Xenon lamp $(\lambda>$ $420 \mathrm{~nm})$ to simulate the solar light source. $\mathrm{Na}_{2} \mathrm{~S} \cdot 9 \mathrm{H}_{2} \mathrm{O}(0.1 \mathrm{M})$ and $\mathrm{Na}_{2} \mathrm{SO}_{3}(0.1 \mathrm{M})$ were dissolved in $80 \mathrm{ml}$ of deionized water and poured into the flask, followed by the addition of $25 \mathrm{mg}$ $\mathrm{ZnO} / \mathrm{CdS}$ powder. In order to disperse the powder evenly in the solution, the flask was placed in a supersonic instrument for ultrasonic dispersion of $5 \mathrm{~min}$, then the solution was stirred again for 3 to $5 \mathrm{~min}$. After repeating the above operations 3 times, the flask was filled with nitrogen for 15 min to exclude air. The flask was placed in the middle position of a Xenon lamp source (current $10 \mathrm{~A}$, power $300 \mathrm{~W}$, filter: $\lambda>420 \mathrm{~nm}$ ), and the speed of magnetic stirring was set to $700 \mathrm{rpm}$. The spectrum of 
filter indicates there is no UV leaking (Fig. S1†). The distance between light source and flask is $15 \mathrm{~cm}$. The temperature of the reactor flask is controlled by air conditioner with constant temperature at $24{ }^{\circ} \mathrm{C}$. Irradiation under the Xenon lamp occurred for $2 \mathrm{~h}$ with sampling and testing every half hour. During sampling, the sampler of the gas chromatograph was inserted into the rubber plug of the flask to absorb $0.4 \mathrm{ml}$ gas, which caused the gas to enter the chromatograph quickly, followed by immediate measurement readings.

\section{Results and discussions}

The morphology and structure of the $\mathrm{ZnO}$ products were observed by SEM and TEM. SEM images show that ZnO powders exhibit a three-dimensional floral structure with an average diameter of $2 \mathrm{~m}$ and are assembled by a large amount of flat nanosheets (Fig. 1a-c). The nanosheets exhibit a thickness of about $10 \mathrm{~nm}$ (Fig. 1d and e) and a single crystal structure with an interplanar spacing of $0.28 \mathrm{~nm}$, corresponding to the (100) planes of $\mathrm{ZnO}$ (Fig. 1e). Fig. 1f shows that the nanosheets are composed of nanorods with the same orientation; the gaps between nanorods are marked by red arrow. During the formation of nanosheets, the nanorods may directionally growth and gradually merge into a perfect nanosheet (Fig. S2 $\dagger$ ). In order to explore the effect of alkali on the structure of $\mathrm{ZnO}$, various concentrations of $\mathrm{NaOH}$ were added into the reaction system (Fig. S3 and S4 $\dagger$ ). Smooth platelets were observed in ZnO@2 : 6 (1.2 g NaOH), while the needle-like building blocks appeared in $\mathrm{ZnO}$ @2: 8 (1.6 $\mathrm{g} \mathrm{NaOH})$, suggesting that higher $\mathrm{NaOH}$ content may promote the formation of $\mathrm{Zn}(\mathrm{OH})_{2}$ (Fig. S5 $\dagger$ ). With the decrease of $\mathrm{NaOH}$ content, spherical products were obtained and assembled by close packing nanosheets (Fig. S4 $\dagger$ ). In addition, the structure of $\mathrm{ZnO}$ was broken when the reaction temperature was $50{ }^{\circ} \mathrm{C}$.

To facilitate the deposition of $\mathrm{CdS}$ on the surface of $\mathrm{ZnO}$

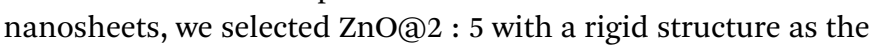
experimental sample. After incubating $\mathrm{ZnO}$ with $\mathrm{Cd}^{2+}$ and $\mathrm{S}^{2-}$, the whole structure was maintained (Fig. $2 a$ and b), and CdS nanoparticles with a $5 \mathrm{~nm}$ diameter were observed on $\mathrm{ZnO}$ nanosheets (Fig. 2c). In the TEM image, the selected area electron diffraction (SAED) indicates the coexistence of $\mathrm{ZnO}$ and

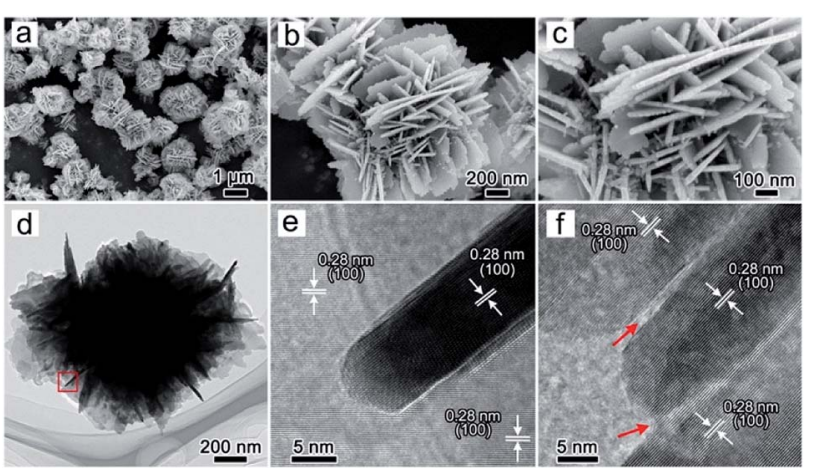

Fig. 1 SEM $(a-c)$ and TEM (d-f) images of the flower-like $\mathrm{ZnO}$ (ZnO@2 : 5) incubated at $40{ }^{\circ} \mathrm{C}$ for 6 hours.

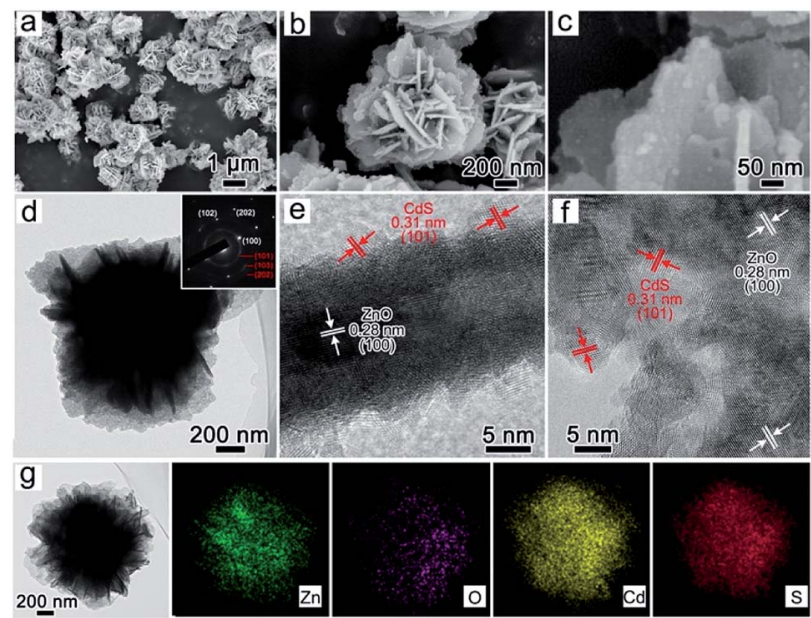

Fig. 2 SEM $(a-c)$ and TEM ( $d-f)$ and EDS ( $g$ ) of the $\mathrm{ZnO} / \mathrm{CdS}$ heterostructures (the inset in part $\mathrm{d}$ is the SAED of the $\mathrm{ZnO} / \mathrm{CdS}$ composite).

CdS (Fig. 2d and inset). The single crystal-like spots result from the $\mathrm{ZnO}$ nanosheets, and the ring diffraction pattern is responded to the random deposition of CdS nanoparticles. The XRD patterns also verify the phase components in the composites (Fig. 3a and S6†). The coating of CdS nanoparticles on $\mathrm{ZnO}$ nanosheets is visible from the exterior spaces of the vertical and horizontal nanosheets in Fig. 2e and $\mathrm{f}$. The crystal plane spacing of 0.31 and $0.28 \mathrm{~nm}$ is attributed to the exposed crystal plane of CdS (101) and $\mathrm{ZnO}(100)$ planes, and the specific surface areas of $\mathrm{ZnO} @ 2: 5$ and $\mathrm{ZnO} / \mathrm{CdS}$ were determined to be
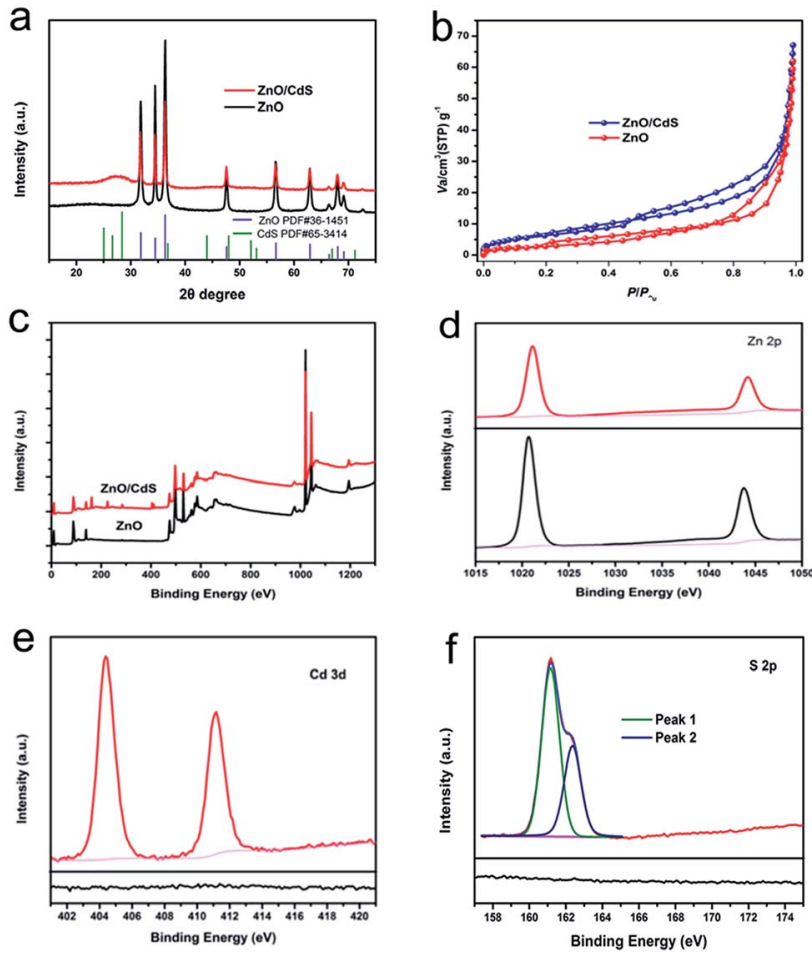

Fig. 3 XRD (a), BET (b) and XPS spectra (c) of $\mathrm{ZnO}$ and $\mathrm{ZnO} / \mathrm{CdS}$. High resolution XPS spectrum of $\mathrm{Zn} 2 \mathrm{p}$ (d), $\mathrm{Cd} 3 \mathrm{~d}$ (e) and $S 2 \mathrm{p}$ (f). 
17.2 and $28.4 \mathrm{~m}^{2} \mathrm{~g}^{-1}$, respectively. The increase in the specific surface areas of $\mathrm{ZnO} / \mathrm{CdS}$ may be attributed to the CdS nanoparticles. Fig. $2 \mathrm{~g}$ and $\mathrm{S} 7 \dagger$ exhibits the uniform distribution of $\mathrm{Zn}, \mathrm{O}, \mathrm{Cd}$, and $\mathrm{S}$ elements in the $\mathrm{ZnO} / \mathrm{CdS}$ heterostructure. As a control group, the CdS powder with aggregated nanoparticles was individually synthesized through directly mixing $\mathrm{Cd}^{2+}$ and $\mathrm{S}^{2-}$ (Fig. S8 $\dagger$ ). The EDS mapping of CdS nanoparticles and $\mathrm{ZnO}$ flower was presented in Fig. S9. $\dagger$

The chemical composition of $\mathrm{ZnO} / \mathrm{CdS}$ was further analyzed by XPS. Fig. $3 c$ shows the measurement spectra, from which the peaks of elements in sample $\mathrm{ZnO}$ and $\mathrm{ZnO} / \mathrm{CdS}$ can be clearly observed. The high-resolution XPS spectrum of $\mathrm{Zn} 2 \mathrm{p}_{3 / 2}$ and $\mathrm{Zn}$ $2 \mathrm{p}_{1 / 2}$ shows respective peaks centered at 1021.8 and $1044.9 \mathrm{eV}$ (Fig. 3d), where the spin orbit separation of about $23.1 \mathrm{eV}$ is ascribed to $\mathrm{Zn}^{2+}$ in $\mathrm{ZnO}^{28}$ Compared with pure $\mathrm{ZnO}$, the weak shift of $\mathrm{Zn}$ peaks in $\mathrm{ZnO} / \mathrm{CdS}$ indicates the chemical bonding between $\mathrm{ZnO}$ and CdS. The $\mathrm{Cd} 3 \mathrm{~d}$ orbital region (Fig. 3e) reveals the binding energies of $\mathrm{Cd} 3 \mathrm{~d}_{5 / 2}$ and $\mathrm{Cd} 3 \mathrm{~d}_{3 / 2}$ peaks at 405.1 and $411.8 \mathrm{eV}$, respectively, where the splitting energy of $6.7 \mathrm{eV}$ is a characteristic value of $\mathrm{Cd}$ atoms in CdS. Further, Fig. $3 \mathrm{f}$ displays two bonding energy S 2p peaks at 161.5 and $162.5 \mathrm{eV}$, which are indicative of CdS.

Changing the concentration of $\mathrm{Cd}^{2+}$, we modified the amount of CdS deposited on $\mathrm{ZnO}$. When the concentration ratio of $\mathrm{Zn}$ to Cd was $10: 1$, a composite with structural integrity was obtained with visibly apparent CdS nanoparticles (Fig. 4a). Increasing the ratio from $8: 1$ to $2: 1$, the composite with unchanged structure were synthesized, and the loading of CdS in $\mathrm{ZnO}$ may increase (Fig. 4b-d). At the same time, the compositions of the samples were not changed through XRD
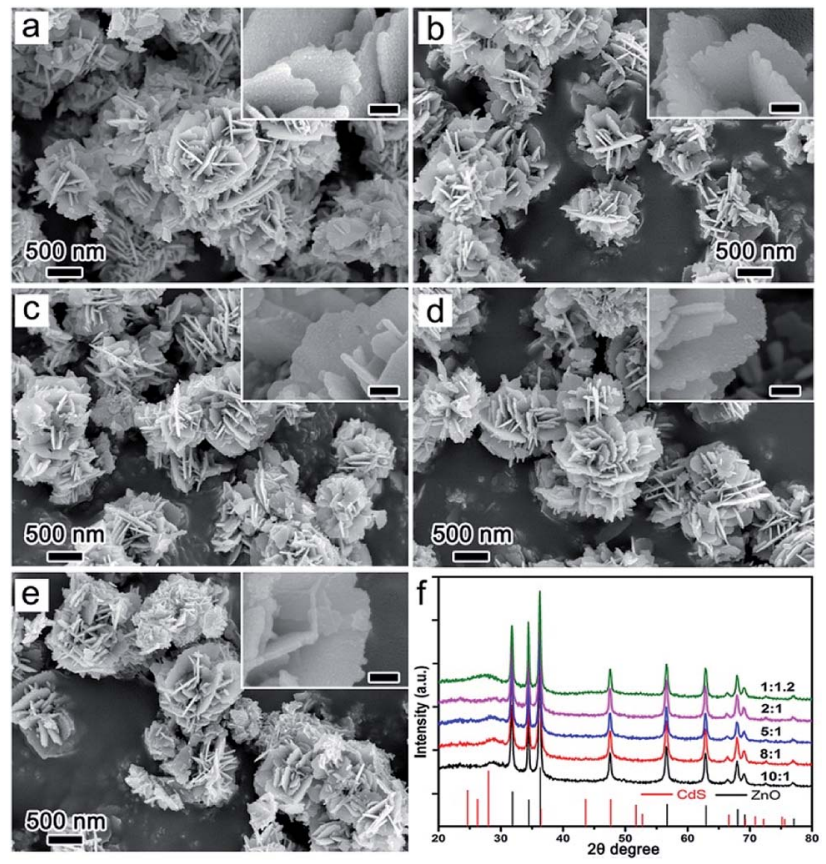

Fig. 4 SEM (a-e) and XRD ( $\mathrm{f}$ ) of the products at different reaction concentration ratio of $\mathrm{S}$ and $\mathrm{Cd}$ ((a) $10: 1$, (b) $8: 1$, (c) $5: 1$, (d) $2: 1$, (e) $1: 1.2)$. patterns (Fig. $4 \mathrm{f}$ and $\mathrm{S} 10^{\dagger}$ ). However, when the ratio was $1: 1.2$, some nanowire-like products appeared on the $\mathrm{ZnO}$ nanosheets, meaning the impurity phase was synthesized (Fig. 4e). The impurity phase of $\mathrm{Cd}(\mathrm{OH})_{2}$ was detected in samples with $1: 2$ ( $\mathrm{Zn}: \mathrm{Cd}$ ), and the flower-like structure collapsed (Fig. S11 $\dagger$ ). Since the alkalinity of the $\mathrm{S}^{2-}$ solution can cause destruction of the $\mathrm{ZnO}$ structure, we changed the load order of $\mathrm{S}^{2-}$ (first) and $\mathrm{Cd}^{2+}$ (second) on the $\mathrm{ZnO}$ nanosheets to prevent this breakage. This resulted in a load effect similar to previous and the structure of the product did not change much (Fig. S12 and $\mathrm{S} 13 \dagger)$. The deposition of CdS on $\mathrm{ZnO}$ can also be demonstrated in TEM images (Fig. S14†). To investigate the effect of the formation of $\mathrm{ZnO} / \mathrm{CdS}$ heterostructure on optical band gap, we tested the UV-vis spectra of pure $\mathrm{ZnO}$ and $\mathrm{ZnO} / \mathrm{CdS} 1: 1$ (Fig. S15 $\dagger$ ). It illustrates that the optical band gap of $\mathrm{ZnO} / \mathrm{CdS}$ $1: 1(2.1 \mathrm{eV})$ is narrower than pure $\mathrm{ZnO}(3.1 \mathrm{eV})$. The band gap of CdS nanoparticle is $2.2 \mathrm{eV}$ (Fig. S16 $\dagger$ ). The XPS valence spectra of CdS and $\mathrm{ZnO}$ are presented in Fig. S17. $\dagger$ The PL spectra of the pure $\mathrm{ZnO}$ and $\mathrm{ZnO} / \mathrm{CdS} 1: 1$ which excited at $325 \mathrm{~nm}$ is showed in Fig. S18, $\dagger$ it is obviously that compared with pure $\mathrm{ZnO}$, the peak of $\mathrm{ZnO} / \mathrm{CdS} 1: 1$ has a red shift of $25 \mathrm{~nm}$.

The photocatalytic capability of splitting water over these samples was measured under irradiation of $420 \mathrm{~nm}$ using the Xenon lamp and $\mathrm{Na}_{2} \mathrm{~S}$ and $\mathrm{Na}_{2} \mathrm{SO}_{3}$ as sacrificial agents. It can be
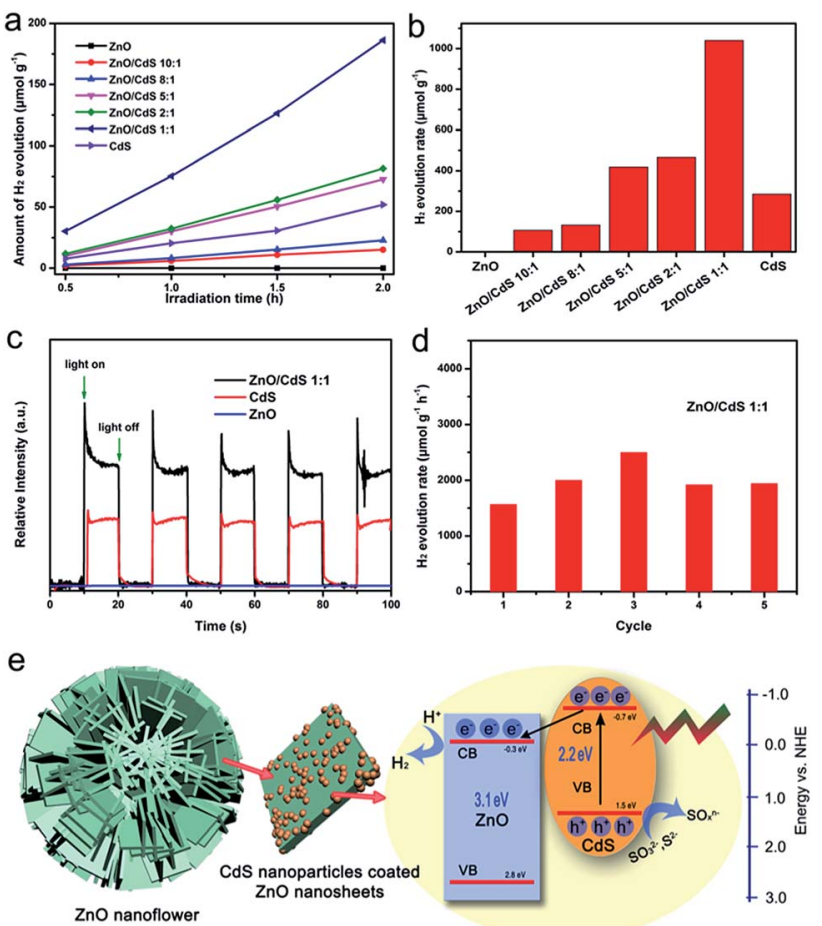

Fig. 5 Comparison of the hydrogen production at different time points (a) and the photocatalytic hydrogen evolution rate (b) over different samples during $2 \mathrm{~h}$; (c) is the photocurrent responses under visible-light $(\lambda>420 \mathrm{~nm})$ irradiation; (d) is the cycling runs of the $\mathrm{ZnO} /$ CdS ( $1: 1)$ photocatalyst, each cycle takes two hours; (e) is the $\mathrm{ZnO} /$ CdS heterostructures' photo-catalytic hydrogen production mechanism. 
seen in Fig. 5a and $\mathrm{b}$ that pure $\mathrm{ZnO}$ produced almost no hydrogen due to its wide band gap, which prevents excitation of $\mathrm{ZnO}$ to produce photogenerated electron and holes under visible light. As the loading of CdS in the $\mathrm{ZnO} / \mathrm{CdS}$ heterostructure increased, hydrogen production and the hydrogen production rate of the samples ( $\mathrm{ZnO}: \mathrm{CdS})$ increased to 106.7 (10:1), 132.3 (8: 1), 418.4 (5: 1), 465.7 (2: 1), 1040.5 (1:1), and $284.6(\mathrm{CdS}) \mathrm{mol} \mathrm{g}^{-1} \mathrm{~h}^{-1}$. For $5: 1$ (ZnO : CdS), the amount of hydrogen produced and the rate of hydrogen production exceeded that of CdS without ZnO. In the Fig. 5c, it shows the photocurrent response of different photocatalysts. Compared with the pure $\mathrm{ZnO}$ and $\mathrm{CdS}$, the $\mathrm{ZnO} / \mathrm{CdS}$ photocatalysts $(1: 1)$ we prepared here shows higher photo-current response, demonstrating that the separation between photogenerated electrons and holes in this prepared $\mathrm{ZnO} / \mathrm{CdS}$ heterostructure is more efficient, which is significant to improve the photocatalytic activity. Meanwhile, the photocurrent of $\mathrm{ZnO} / \mathrm{CdS} 2: 1 /$ $5: 1 / 8: 1 / 10: 1$ was presented in Fig. S19. $\dagger$ According to the relative intensity of photocurrent, it is confirmed that the content of $\mathrm{CdS}$ in $\mathrm{ZnO} / \mathrm{CdS}$ is proportional to the photocurrent. In order to verify the stability of the $\mathrm{ZnO} / \mathrm{CdS}$ heterostructure $(1: 1)$, we also take the recycling photocatalytic performance under the same conditions (Fig. 5d). From the data, it can be seen that the $\mathrm{H}_{2}$-production rate of the $\mathrm{ZnO} / \mathrm{CdS}(1: 1)$ sample within five cycles in 10 hours is relatively stable. Fig. 5e shows the photocatalytic hydrogen production mechanism of $\mathrm{ZnO} /$ CdS heterojunction where the CdS nanoparticles loaded on the $\mathrm{ZnO}$ nanosheets formed a heterojunction, which is further described as follows. According to the band gap from UV-vis absorption spectra and XPS valence spectra, the alignment modelling was presented. Under illumination, the semiconductor CdS absorbs visible light energy and excites the electron to transition from the valence band to the conduction band and form photogenerated electron-hole pairs. Then, the photogenerated electrons in the CdS conduction band migrate to the conduction band of $\mathrm{ZnO}$ through the heterojunction, which inhibits the combination of photogenerated electrons and holes. Photogenerated carriers migrated to the surface of $\mathrm{ZnO}$ to produce hydrogen and hole oxidation of $\mathrm{S}^{2-}$ and $\mathrm{SO}_{3}{ }^{2-}$ on CdS. Therefore, the $\mathrm{ZnO} / \mathrm{CdS}$ heterostructure exhibits better photocatalytic capability than pure CdS.

\section{Conclusions}

In summary, we propose a low temperature and simple synthesis method to fabricate a $\mathrm{ZnO} / \mathrm{CdS}$ heterostructure based on flower-like $\mathrm{ZnO}$ assembled by nanosheets. By continuously combining $\mathrm{Cd}^{2+}$ and $\mathrm{S}^{2-}$, CdS nanoparticles were deposited on $\mathrm{ZnO}$ nanosheets. However, when the ratio of $\mathrm{Zn}: \mathrm{Cd}$ was higher than $1: 1$, the structure of the products could not be maintained, and the ZnO nano-flower structure with nanosheets was broken. Results suggest that the photo-catalytic efficiency of the prepared $\mathrm{ZnO} / \mathrm{CdS}$ composites is much higher than those of pure $\mathrm{ZnO}$ and CdS and depends on the loading content of CdS. It was also found that with the increase in the loading amount of CdS, hydrogen production is enhanced. When $\mathrm{ZnO}$ : CdS was in a $1: 1$ ratio, its hydrogen production rate reached 1040.5 $\mu \mathrm{mol} \mathrm{g}^{-1} \mathrm{~h}^{-1}$ without Pt loading. Overall, this work may provide a green and efficient approach to construct the heterostructures for solar-to-fuel conversion and serve as a motivational basis to explore other photocatalysts in hydrogen production.

\section{Conflicts of interest}

The authors declare no competing financial interest.

\section{Acknowledgements}

This work was funded by the National College Students Innovation and Entrepreneurship Training Program (201810497026). We are grateful to Miss Bi-Chao Xu of the Core Facility and Technical Support, Wuhan Institute of Virology for her technical support in sample preparation. The authors declare that they have no conflict of interest.

\section{Notes and references}

1 J. Low, J. Yu, M. Jaroniec, S. Wageh and A. A. Al-Ghamdi, Adv. Mater., 2017, 1601694.

2 N. Chouhan, R. Ameta, R. K. Meena, N. Mandawat and R. Ghildiyal, Int. J. Hydrogen Energy, 2016, 41, 2298-2306.

3 D. Ma, J. W. Shi, Y. Zou, Z. Fan, X. Ji and C. Niu, ACS Appl. Mater. Interfaces, 2017, 9, 25377-25386.

4 D. Ma, J. W. Shi, Y. Zou, Z. Fan, X. Ji, C. Niu and L. Wang, Nano Energy, 2017, 39, 183-191.

5 J. X. Lv, Z. M. Zhang, J. Wang, X. L. Lu, W. Zhang and T. B. Lu, ACS Appl. Mater. Interfaces, 2019, 11, 2655-2661.

6 J. K. Vaishnav, S. S. Arbuj, S. B. Rane and D. P. Amalnerkar, RSC Adv., 2014, 4, 47637-47642.

7 A. Fujishima and K. Honda, Nature, 1972, 238, 37-38.

8 S. R. Lingampalli, U. K. Gautam and C. N. R. Rao, Energy Environ. Sci., 2013, 6, 3589-3594.

9 P. Zhou, J. G. Yu and M. Jaroniec, Adv. Mater., 2014, 26, 49204935.

10 G. R. Yang, W. Yan, Q. Zhang, S. H. Shen and S. J. Ding, Nanoscale, 2013, 5, 12432-12439.

11 J. Jin, C. Wang, X. N. Ren, S. Z. Huang, M. Wu, L. H. Chen, T. Hasan, B. J. Wang, Y. Li and B. L. Su, Nano Energy, 2017, 38, 118-126.

12 G. Lia, Z. Lian, W. Wang, D. Zhang and H. Li, Nano Energy, 2016, 19, 446-454.

13 H. Moa, C. Song, Y. Zhou, B. Zhang and D. Wang, Appl. Catal., B, 2018, 221, 565-573.

14 W. Liu, X. Wang, H. Yu and J. Yu, ACS Sustainable Chem. Eng., 2018, 6, 12436-12445.

15 X. Wang, Q. Li, P. Shi, J. Fan, Y. Min and Q. Xu, Small, 2019, 15, 1901530.

16 S. Gong, Z. Jiang, P. Shi, J. Fan, Q. Xu and Y. Min, Appl. Catal., B, 2018, 238, 318-327.

17 T. Wu, Y. Ma, Z. Qu, J. Fan, Q. Li, P. Shi, Q. Xu and Y. Min, ACS Appl. Mater. Interfaces, 2019, 11, 5136-5145.

18 K. Liao, S. Chen, H. Wei, J. Fan, Q. Xu and Y. Min, J. Mater. Chem. A, 2018, 6, 23062-23070. 
19 S. G. Kumar and K. S. R. Koteswara Rao, RSC Adv., 2015, 5, 3306-3351.

20 S. Cho, J.-W. Jang, J. S. Lee and K.-H. Lee, Langmuir, 2010, 26, 14255-14262.

21 R. Lv, T. Wang, F. L. Su, P. Zhang, C. J. Li and J. L. Gong, Nano Energy, 2014, 7, 143-150.

22 S. Khanchandani, S. Kundu, A. Patra and A. K. Ganguli, J. Phys. Chem. C, 2012, 116, 23653-23662.

23 S. Tso, W. S. Li, B. H. Wu and L. J. Chen, Nano Energy, 2018, 43, 270-277.
24 C. Baslak, E. Aslan, I. H. Patir, M. Kus and M. Ersoz, Int. J. Hydrogen Energy, 2016, 41, 20523-20528.

25 X. W. Wang, G. Liu, Z. G. Chen, F. Li, L. Z. Wang, G. Q. Lu and H. M. Cheng, Chem. Commun., 2009, 3452-3454.

26 S. Mukhopadhyay, I. Mondal, U. Pal and P. S. Devi, Phys. Chem. Chem. Phys., 2015, 17, 20407-20415.

27 H. Ping, H. Xie and Z. Fu, Journal of Materiomics, 2017, 3, 8395.

28 G. Yang, W. Yan, Q. Zhang, S. Shen and S. Ding, Nanoscale, 2013, 5, 12432-12439. 